\title{
Dendritic Cells: More Than Just Adaptive Immunity Inducers?
}

\author{
Nathalie Jacobs, Jacques Boniver, Pascale Hubert and Philippe Delvenne*
}

Department of Pathology, CRCE-CBIG, B35, University of Liege, CHU of Liège, B4000 Liege, Belgium

\begin{abstract}
Dendritic cells (DC) are well known for their capacity to induce immune responses and there is also accumulating evidence of their ability to interact with various cell types of the innate system, such as NK, NKT or TCR $\gamma \delta$ cells. These interactions are bi-directional, mediated by soluble or cell surface molecules and have been mainly described in the context of immune responses to infectious agents and tumors.

NK, NKT or TCR $\gamma \delta$ cells induce the maturation of DC, as shown by the increased expression of CD86, IL12 production and priming of T cell responses. On the other hand, mature DC have the ability to activate NK, NKT or TCR $\gamma \delta$ cells for sustained innate immune responses and activated NK cells may kill immature DC. In addition, DC and NK or TCR $\gamma \delta$ cells share similar functions such as cytotoxic and antitumor activity, interferon production and antigen presentation capacity.
\end{abstract}

Keywords: Antigen-presenting cells (APC), dendritic cells (DC), natural killer cells (NK), TCR $\gamma \delta$ cells, NKT cells.

\section{INTRODUCTION}

Historically, the main function of dendritic cells (DC) was defined as the ability to stimulate naïve $\mathrm{T}$ cells. However, pivotal experiments by Fernandez et al. [1] demonstrated that DC also activate NK cells. More recently, this DC activation was extended to other cell types that play a role in natural innate immunity such as NKT or TCR $\gamma \delta$ cells $[2,3]$. Moreover, DC share with natural innate cells the ability to kill tumor cells (Fig. 1).

Conventional DC subsets described in humans include myeloid DC CD11 ${ }^{+}(\mathrm{mDC})$ and plasmacytoid DC CD11c(pDC). When compared to $\mathrm{mDC}, \mathrm{pDC}$ lack expression of some myeloid antigens (CD13, CD33) and lymphoid markers (CD2, CD5, CD7) [4]. In addition, pDC produce large amounts of IFN $\alpha$ in response to viral DNA or RNA [5], suggesting that they play an important role in sensing viral infections. Human mDC also differ from $\mathrm{pDC}$ in their expression pattern of highly conserved microbial pattern recognition receptors, known as toll-like receptors (TLR). Upon ligand recognition by TLR, DC maturation occurs, followed by secretion of numerous cytokines and chemokines [6]. In steady-state conditions, DC are in an immature stage but in an inflammatory microenvironment, they up-regulate surface antigens such as CD80, CD86 and CCR7 and produce high levels of IL12 and TNF $\alpha$ during a process called maturation (for review see [7]).

Natural Killer (NK) cells are a particular population of lymphocytes (for review [8]) that play an important role in innate immunity (for review see [9]). The "NK" name was originally given after the demonstration of NK cells' ability to kill target cells without prior exposure to them or help from another cell population, in contrast to cytolytic $\mathrm{T}$ cells.

NKT lymphocytes are T lymphocytes expressing several NK markers. Upon activation, they are able to produce type

*Address correspondence to this author at the Department of Pathology, B35, CHU of Liège, University of Liège, 4000 Liege, Belgium; Tel: (32) 43662564; Fax: (32) 43662919; E-mail: P.Delvenne@ulg.ac.be
1 as well as type 2 cytokines and display cytotoxic activity [10]. NKT cells bearing an invariant TCR (Vo14Jo28 gene segments in mice and $\mathrm{V} \alpha 24 \mathrm{~J} \alpha \mathrm{Q}$ in humans) are designated as iNKT cells and are restricted by nonpolymorphic CD1d molecules [11]. One example of a natural CD1d ligand is the lypophosphoglycan from the surface glycocalyx of parasites, which stimulates IFN $\gamma$ secretion by a subset of NKT cells [12]. Like NK cells, NKT cells can detect altered self-ligands such as ganglioside GD3, overexpressed on human melanoma cells [13]. Therefore, both self and microbial glycolipids presented on CD1d molecules can induce NKT activation. NKT cells are involved in a large number of immune responses including autoimmunity [14] and immunity against viral [15], bacterial [16], fungal [17], parasitic pathogens [18] and tumors [19].

TCR $\gamma \delta \mathrm{T}$ cells represent a distinct subset of T cells characterized by a T cell receptor (TCR) with unique structural and antigen-binding features which are different from the classical TCR composed of $\alpha$ and $\beta$ chains [20]. In contrast to the antigen-recognition by TCR $\alpha \beta \mathrm{T}$ cells, TCR $\gamma \delta$ cells do not need any antigen-presenting cell (APC) for the recognition of foreign epitopes [23]. Various populations of $\mathrm{TCR} \gamma \delta$ cells reside in the peripheral tissues of mice, including the skin, gut and uterus. Each tissue has its own specific subset of TCR $\gamma \delta$ cells, according to the variable (V) gene used to generate the TCR. Resident TCR $\gamma \delta$ cells represent a first line of defense against infection and exert tissue-specific immune functions. However, in humans, tissue-specific $\mathrm{TCR} \gamma \delta$ cells are not as prominent. Indeed, the adult human TCR $\gamma \delta$ cell repertoire is dominated by a polyclonal population bearing the $\mathrm{V} \gamma 2 \mathrm{~V} \delta 2 \mathrm{TCR}$ and representing 2 to $8 \%$ of peripheral blood $\mathrm{T}$ cells. $\mathrm{V} \gamma 2 \mathrm{~V} \delta 2 \mathrm{~T}$ cells recognize phosphorylated isoprenoid precursors and alkylamines which are conserved in the metabolic pathways of many species including plants, pathogens and primates [21]. These cells expand in the presence of many different infectious agents including mycobacteria. In the periphery, TCR $\gamma \delta$ cells express mostly the V $\delta 1$ TCR [22]. TCR $\gamma \delta$ cells display a range of NK cell functions including the rapid secretion of chemokines and cytokines and target cell lysis (for review see [20]). TCR $\gamma \delta$ 


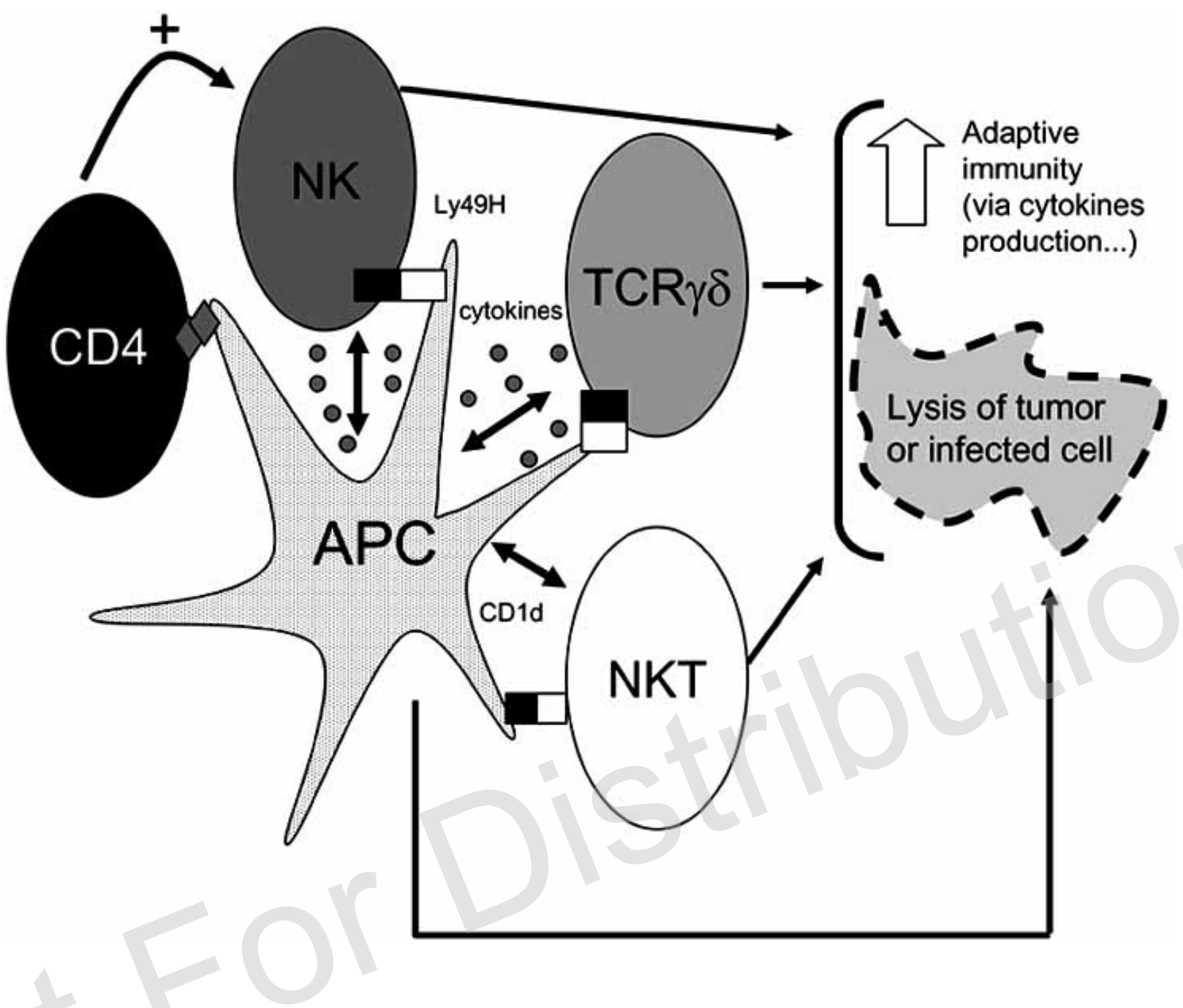

Fig. (1). Schematic representation of the central role of antigen-presenting cells (APC) in the natural immunity.

cells are key players of innate immunity, and arguably the most complex and advanced cellular representative of the innate immune system (for review [24]).

\section{INTERACTIONS BETWEEN DENDRITIC CELLS AND NATURAL KILLER CELLS}

The first evidence for the role of DC in natural immunity was provided by the work of Fernandez et al. [1] which showed a direct activation of NK cells by DC in vivo. Subsequently, the DC/NK interactions were found to be multidirectional [25]. Although $\mathrm{NK}$ cell activation in vitro has been documented by using a variety of mouse or human DC [9], most studies focused on the interactions between $\mathrm{NK}$ cells and $\mathrm{mDC}$, even though $\mathrm{NK}$ cells also have the ability to interact with pDC [25]. For example, upon stimulation through TLR9, pDC can activate NK cells to kill various tumor cells [26].

It is still unclear whether the DC maturation status influences their ability to activate NK cells. In some studies, immature DC require a maturation stimulus to activate NK cells [27], whereas other reports show that immature and mature DC are equivalent in their ability to activate NK cells [28, 29].

The in vivo relevance of $\mathrm{NK}$ cell activation by $\mathrm{DC}$ is demonstrated in murine tumors [1] and viral models [30] and is related to a particular DC subset expressing CD8 $\alpha+$. After infection of $\mathrm{C} 57 \mathrm{Bl} / 6$ mice with cytomegalovirus, the expansion of NK cells induced by DC was shown to specifically involve the Ly49H receptor on NK cells [9]. On the other hand, NK cells can respond to polyinosinic-polycytidylic acid (poly(I:C)), a synthetic mimic of viral RNA, directly via TLR3 and independently from DC [31]. In bacterial infections, interactions between $\mathrm{NK}$ cells and DC also result in the rapid induction of NK cell activation and in the lysis of uninfected DC.

The DC-induced activation of resting NK cells in vitro requires direct cell contacts resulting in a polarized secretion of preassembled stores of IL12 by DC towards NK cells within the synapse between both cell types [32]. Cytokines such as IL18, IL15, IL2 and type I interferon also play a crucial role in this cross-talk, for example, murine DC require the presence of IL-15R to prime NK cells [33], and IL2-deficient DC are severely impaired in their ability to 
activate NK-cell response both in vitro and in vivo, as revealed by antibacterial and antitumor responses [27]. It seems that the different subsets of DC activate NK cells at several steps of the immune response, with the pDC promoting early activity of $\mathrm{NK}$ cells followed by $\mathrm{mDC}$ stimulation and finally activation of a subpopulation of $\mathrm{NK}$ cells (Ly49H+) by mDC. Early release of IL12 by pathogenactivated DC could be the link between $\mathrm{NK} / \mathrm{mDC}$ and $\mathrm{NK} / \mathrm{pDC}$ interactions [26].

Conversely, NK cells can activate DC. Optimal DC in vitro activation by NK cells requires both cell-cell contacts and TNF $\alpha$ production [29]. Cell-cell contacts can be mediated via the receptor NKp30, and inhibitory receptors including some Killer Immunoglobulin-like Receptors (KIR) or NKG2A receptors can negatively regulate this activation [35]. In lymph nodes, NK cells may have an important role in the initiation of $\mathrm{T}$-cell responses by contributing to $\mathrm{DC}$ maturation. Indeed, under in vitro conditions where DC are suboptimally activated with type-I IFN, NK cells license DC to prime T-cell responses [36]. In some cases, T-cellmediated tumor rejection is dependent on DC activation by NK cells [37]. Type-I IFN secreted during NK-cell-mediated tumor rejection is critical for CTL generation, particularly when tumors express CD70, CD80 or CD86 [38]. Furthermore, Adam et al. [39] reported that NK-cell-DC crosstalk may bypass the $\mathrm{T}$ helper arm in CTL induction against tumors expressing NKG2D ligands.

In contrast, activated $\mathrm{NK}$ cells can also kill immature uninfected DC [40] or graft-derived DC in transplant models [41]. Killing of DC by activated NK cells may negatively regulate inflammatory responses [42]. Among NK receptors, NKp30 seems to play an important role in the maturation and control of apoptosis in DC. However, the up-regulation of HLA-E expression on DC protects them from NK lysis through the CD94/NKG2A inhibitory receptor [43]. The interactions between NK cells and DC via NKp30 differ according to the ratio between NK cells and DC. A low $\mathrm{NK} / \mathrm{DC}(1 / 5)$ ratio results in DC activation whereas at high (5/1) ratio, NK cells kill immature DC [28, 29]. In contrast, pDC seem to display an intrinsic resistance to lysis by NK cells but exposure of pDC to IL3 increases their susceptibility to NK cell cytotoxicity [25]. Until now, DC killing by NK cells in vivo has been demonstrated only in murine transgenic [42] or transplantation models with no evidence so far that DC killing occurs in vivo under normal physiologic conditions.

As well as the NK-cell-DC-T-cell sequence, a DC-T-cellNK-cell pathway has also been identified in vivo. Van Den Broeke et al. [44] reported that an injection of unpulsed mature bone marrow-derived DC protects $\mathrm{BALB} / \mathrm{C}$ mice against syngeneic CT26 colon carcinoma or LL/2 lung carcinoma inoculation and that the tumor protection is mediated by NK cells. Activation of NK cells is CD4 T-celldependent and relies strongly on the expression of costimulatory molecules on DC, suggesting that mature DC stimulate CD4 $\mathrm{T}$ cells that can, subsequently, directly activate NK cells through IL-2 secretion [44].

Since the interactions between NK cells and DC require cell contacts, there must be a common meeting ground for these cells, recently proposed as lymph nodes or inflammation sites (for review see [45]). For example, NK cells and
DC are in direct contact in dermal sites of yeast infection [46], and CD56 ${ }^{\text {bright }} \mathrm{NK}$ cells are present in normal resting lymph nodes in close proximity to activated DC [47]. In mice, injection of mature DC promotes rapid recruitment of NK cells to lymph nodes in a CCR7-independent, CXCR3dependent manner [48], whereas they are excluded from these tissues under normal conditions. Interestingly, $\mathrm{pDC}$ express homing molecules similar to those expressed by CD56 $6^{\text {bright }} \mathrm{NK}$ cells, including L-selectin, CXCR3 and, after activation, CCR7. Therefore, $\mathrm{pDC}$ are likely to migrate from the blood through high endothelial venules just as NK cells do, before co-localising in the lymph node and activating each other. In inflammation sites, such as the skin from patients infected with some types of yeast, increased numbers of NK cells have also been demonstrated in close proximity to $\mathrm{DC}$, providing evidence for NK-DC contacts in peripheral tissues in vivo [46].

\section{INTERACTIONS BETWEEN DENDRITIC CELLS AND NATURAL KILLER T LYMPHOCYTES}

Natural Killer T (NKT) cells bearing an invariant TCR (iNKT) need DC to become activated, as shown by the stimulation of human $\mathrm{V} \alpha 24^{+} \mathrm{CD} 8^{+} \mathrm{NKT}$ cells in the presence of monocyte-derived DC pulsed with $\alpha$-Galactosylceramid ( $\alpha$-GalCer). On the other hand, Kitamura et al. [49] suggested that iNKT are able to activate DC and to modulate the adaptive immune response induced by them. The interaction of NKT cells with antigen-capturing DC allows the induction of antigen-specific, IFN $\gamma$-producing $\mathrm{CD} 4+$ and $\mathrm{CD} 8+\mathrm{T}$ cells. Murine DC maturation has been documented in vitro and in vivo after iNKT cell stimulation by the synthetic $\alpha$ GalCer presented by CD1d molecules on DC [50] and iNKT cells have been proposed to have a CD40 signaling mediated adjuvant effect for $\mathrm{T}$ cell-mediated immunotherapy [50, 51]. These data suggest that DC activated by a population of innate lymphocytes, such as NKT cells, can activate another group of innate lymphocytes, such as NK cells, to induce antitumor effects. In addition, other data suggest that iNKT cells mediate a cross-talk between DC subsets ( $\mathrm{mDC}$ and pDC) known to express mutually exclusive TLR and cytokine profiles [52].

Like NK cells, NKT cells could also, under certain conditions, kill both immature and mature DC. These cells expressing inhibitory NK receptors are restricted by HLA-E molecules and are able to kill most NK-susceptible tumor cell lines [53]. Interestingly, in Leishmania infantum infections, immature DC up-regulate CD1d and are efficiently killed by NKT cells, whereas they are resistant to NK cellmediated lysis due to an up-regulation of HLA-E expression which protects them through the inhibitory receptor CD94/NKG2A on NK cells [54].

\section{INTERACTIONS BETWEEN DENDRITIC CELLS AND TCR $\gamma \delta$ CELLS}

In 1996, Yokota et al. [55], suggested that an interaction occurs between TCR $\gamma \delta$ and APC, since murine Langerhans cells (LC), a sub-family of DC localized in squamous epithelium, are in close contact with $\mathrm{TCR} \gamma \delta$ cells. Contacts between TCR $\gamma \delta$ and DC are also detected in the murine lung [24] and compared to TCR $\alpha \beta$ T cells, TCR $\gamma \delta$ cells are more frequently found in connection with macrophages and DC 
[56]. Finally, evidence was provided that TCR $\gamma \delta \mathrm{T}$ cells control the recruitment and differentiation of peritoneal macrophages in the presence of a bacterial infection [57].

Here again, the TCR $\gamma \delta$ cells-DC interactions are bidirectional $[3,58]$. TCR $\gamma \delta$ are activated by DC infected in vitro by the Bacille Calmette-Guerin (BCG) as indicated by elevated CD69 expression on their cell surface, IFN $\gamma$ secretion and cytotoxic activity. Consequently DC-stimulated TCR $\gamma \delta$ cells help the DC to prime a significantly stronger antimycobacterial CD8 T cell response [3]. Activation of TCR $\gamma \delta$ cells with isopentenyl pyrophosphate (IPP) or aminobiphosphonates (pamidronate; PAM) led to a significant upregulation of CD86 and MHC class I molecules and to the acquisition of functional features typical of activated DC [58]. Cell-cell contacts are required for stimulation with PAM but not IPP [58]. In return, DC induce CD25 and CD69 up-regulation on TCR $\gamma \delta$ cells as well as IFN $\gamma$ and TNF $\alpha$ secretion by TCR $\gamma \delta$ cells [58]. TCR $\gamma \delta$ cells activated by the synthetic phosphoantigen bromohydrin pyrophosphate (BrHPP) induce the production of IL12 by DC, an effect involving IFN $\gamma$ production. The relevance of this finding to DC function was demonstrated by the increased production of IFN $\gamma$ by alloreactive T cells when stimulated in a mixed leukocyte reaction with DC preincubated in the presence of activated TCR $\gamma \delta$ cells. These data suggest that TCR $\gamma \delta$ cell activation results in DC maturation and therefore enhanced $\mathrm{TCR} \alpha \beta \mathrm{T}$ cell responses.

\section{AND "NATURAL CELLS" SHARE SIMILAR FUNCTIONS}

Besides their APC function, DC may acquire cytotoxic properties [59, 60], for example in response to stimulation with type I IFN [61]. In fact, human DC can induce in vitro growth arrest and apoptosis of tumor cells [60, 62, 63]. DC able to kill tumor cells have been also described in rat models [64]. Cytotoxic DC activity seems to be independent of Fas-associated death domain but dependent on caspase-8 [60], whereas the DC negative effect on tumor proliferation is likely to be caspase- 8 independent and does not require cell contacts [63].

Recently, Taieb et al. [65] described a new subset of murine DC involved in tumor surveillance. These cells are $\mathrm{CD} 11 \mathrm{c}^{+} \mathrm{B} 220^{+} \mathrm{Ly} 6 \mathrm{C}^{-}$and express NK markers such as NK1.1 and NKG2D. They produce large amounts of type I IFN, IFN $\gamma$ and IL12 and may kill cells lacking self-major histocompatibility complex molecules in a TRAIL-dependent manner. For these reasons, they have been coined "IFNproducing killer dendritic cells (IKDC)" [66]. These cells are found not only in tumors, but also in primary and secondary organs of naïve mice [65]. Although IKDC possess NK markers and functions [66], they constitute a distinct cell population and differ in their developmental origin since $\mathrm{Rag}^{-1} \mathrm{IL}_{2} \mathrm{rg}^{-/-}$mice lack canonical NK cells but possess functional IKDC in the spleen [65]. To date, no exact human equivalent of mouse IKDC has been reported. Other types of DC bearing NK cell receptors have been identified, such as bitypic cells expressing both CD11c and the NK cell marker DX5 in the context of lymphocytic choriomeningitis virus (LCMV) infection [67]. In a mouse autoimmune diabetes model, treatment with CD40L induces the presence of this bitypic- NK/DC regulatory cell population [68]. These cells can kill NK sensitive target cells and present OVA antigen [68].

On the other hand, activated NK cells could become potent APC [69]. After activation, NK cells can up-regulate MHC class II, CD80, and CD86 molecules and acquire independent unique mechanisms of antigen capture and presentation, involving activating receptors such as NKp46, NKp30 and NKG2D [69]. NK cells may also acquire functional APC-like properties after target cell killing [69]. Studies on the $\mathrm{T}$ cell-activating potential of human NK cells in different clinical conditions revealed that a pro-inflammatory, but not immunosuppressive, microenvironment can up-regulate $\mathrm{T}$ cell-activating molecules on NK cells [69]. Even a subtype of TCR $\gamma \delta$ cells ( $\mathrm{V} \delta 2+\mathrm{T}$ cells) upon microbial activation can display antigen and provide enough co-stimulatory signals to induce a strong naïve $\alpha \beta \mathrm{T}$ cell proliferation and differentiation [70]. TCR $\gamma \delta$ cells also express DC activation markers, such as MHC class II, CD80 and CD86 [71]. Expression of MHC class II and ligands for T cell costimulatory molecules is not a guarantee for APC capability since eosinophils, for example, express significant levels of MHC class II and CD86 on their surface after activation but cannot process antigen [72]. The APC function of TCR $\gamma \delta$ cells seems to be associated with the expression of CCR7, allowing their migration to lymph nodes. This expression is early but transient [73] suggesting that the APC function of TCR $\gamma \delta$ cells would be more effective in the early stage of antimicrobial immune processes. The mechanisms controlling antigen uptake and processing in these cells are, however, still unknown and since in vivo studies are understandably difficult to performe in humans, there is no evidence that these cells function as APC.

In conclusion, there is accumulating evidence that DC maturation by innate lymphocytes coordinates innate and adaptive immunity. The interactions between DC and "natural cells" may be particularly critical in situations where immune surveillance requires efficient early innate responses.

\section{ACKNOWLEDGEMENTS}

The authors thank the Belgian Fund for Medical Scientific Research, the Centre Anti-Cancereux près l'Université de Liège, Televie, L. Lacroix and Léon Fredericq funds for their support.

\section{REFERENCES}

[1] Fernandez NC, Lozier A, Flament C, et al. Dendritic cells directly trigger NK cell functions: cross-talk relevant in innate anti-tumor immune responses in vivo. Nat Med 1999; 5: 405-11.

[2] Takahashi T, Chiba S, Nieda M, et al. Cutting Edge: Analysis of Human Valpha24(+)CD8(+) NK T Cells Activated by alphaGalactosylceramide-Pulsed Monocyte-Derived Dendritic Cells. J Immunol 2002; 168: 3140-4.

[3] Dieli F, Caccamo N, Meraviglia S, et al. Reciprocal stimulation of gammadelta $\mathrm{T}$ cells and dendritic cells during the anti-mycobacterial immune response. Eur J Immunol 2004; 34: 3227-35.

[4] Colonna M, Trinchieri G, Liu YJ. Plasmacytoid dendritic cells in immunity. Nat Immunol 2004; 5: 1219-26.

[5] Barchet W, Cella M, Colonna M. Plasmacytoid dendritic cells-virus experts of innate immunity. Semin Immunol 2005; 17: 25361.

[6] Ito T, Wang YH, Liu YJ. Plasmacytoid dendritic cell precursors/type I interferon-producing cells sense viral infection by Toll- 
like receptor (TLR) 7 and TLR9. Springer Semin Immunopathol 2005; $26: 221-9$

[7] Lutz MB, Schuler G. Immature, semi-mature and fully mature dendritic cells: which signals induce tolerance or immunity? Trends Immunol 2002; 23: 445-9.

[8] Vivier E. What is natural in natural killer cells? Immunol Lett 2006.

[9] Hamerman JA, Ogasawara K, Lanier LL. NK cells in innate immunity. Curr Opin Immunol 2005; 17: 29-35.

[10] Lauwerys BR, Garot N, Renauld JC, Houssiau FA. Cytokine production and killer activity of NK/T-NK cells derived with IL-2, IL-15, or the combination of IL-12 and IL-18. J Immunol 2000; 165: $1847-53$.

[11] Lantz O, Bendelac A. An invariant $\mathrm{T}$ cell receptor alpha chain is used by a unique subset of major histocompatibility complex class I-specific CD4+ and CD4-8- T cells in mice and humans. J Exp Med 1994; 180: 1097-106.

[12] Amprey JL, Im JS, Turco SJ, et al. A subset of liver NK T cells is activated during Leishmania donovani infection by CD1d-bound lipophosphoglycan. J Exp Med 2004; 200: 895-904.

[13] Wu DY, Segal NH, Sidobre S, Kronenberg M, Chapman PB. Cross-presentation of disialoganglioside GD3 to natural killer T cells. J Exp Med 2003; 198: 173-81.

[14] Linsen L, Somers V, Stinissen P. Immunoregulation of autoimmunity by natural killer T cells. Hum Immunol 2005; 66: 1193-202.

[15] Albarran B, Goncalves L, Salmen S, et al. Profiles of NK, NKT cell activation and cytokine production following vaccination against hepatitis B. APMIS 2005; 113: 526-35.

[16] Kinjo Y, Tupin E, Wu D, et al. Natural killer T cells recognize diacylglycerol antigens from pathogenic bacteria. Nat Immunol 2006; 7: 978-86

[17] Kawakami K, Kinjo Y, Uezu K, et al. Monocyte chemoattractant protein-1-dependent increase of $\mathrm{V}$ alpha 14 NKT cells in lungs and their roles in Th1 response and host defense in cryptococcal infection. J Immunol 2001; 167: 6525-32.

[18] Korten S, Anderson RJ, Hannan CM, et al. Invariant Valpha14 chain NKT cells promote Plasmodium berghei circumsporozoite protein-specific gamma interferon- and tumor necrosis factor alpha-producing $\mathrm{CD} 8+\mathrm{T}$ cells in the liver after poxvirus vaccination of mice. Infect Immun 2005; 73: 849-58.

[19] Kawano T, Nakayama T, Kamada N, et al. Antitumor cytotoxicity mediated by ligand-activated human V alpha24 NKT cells. Cancer Res 1999; 59: 5102-5.

[20] Hayday AC. $\gamma \delta$ cells: a right time and a right place for a conserved third way of protection. Annu Rev Immunol 2000; 18: 975-1026.

[21] Bukowski JF, Morita CT, Brenner MB. Human gamma delta T cells recognize alkylamines derived from microbes, edible plants, and tea: implications for innate immunity. Immunity 1999; 11: 5765.

[22] Ferrarini M, Ferrero E, Dagna L, Poggi A, Zocchi MR. Human [gamma][delta] $\mathrm{T}$ cells: a nonredundant system in the immunesurveillance against cancer. Trends in Immunology 2002; 23: 14-8.

[23] Morita CT, Li H, Lamphear JG, et al. Superantigen recognition by gammadelta T cells: SEA recognition site for human Vgamma2 $\mathrm{T}$ cell receptors. Immunity 2001; 14: 331-44.

[24] Born WK, Reardon CL, O'Brien RL. The function of gammadelta $\mathrm{T}$ cells in innate immunity. Curr Opin Immunol 2006; 18: 31-8.

[25] Della Chiesa M, Romagnani C, Thiel A, Moretta L, Moretta A. Multidirectional interactions are bridging human NK cells with plasmacytoid and monocyte-derived dendritic cells during innate immune responses. Blood 2006

[26] Romagnani C, Della Chiesa M, Kohler S, et al. Activation of human NK cells by plasmacytoid dendritic cells and its modulation by CD4+ T helper cells and CD4+ CD25hi T regulatory cells. Eur J Immunol 2005; 35: 2452-8.

[27] Granucci F, Zanoni I, Pavelka N, et al. A contribution of mouse dendritic cell-derived IL-2 for NK cell activation. J Exp Med 2004; 200: 287-95.

[28] Ferlazzo G, Tsang ML, Moretta L, et al. Human dendritic cells activate resting natural killer (NK) cells and are recognized via the NKp30 receptor by activated NK cells. J Exp Med 2002; 195: 34351.

[29] Piccioli D, Sbrana S, Melandri E, Valiante NM. Contact-dependent stimulation and inhibition of dendritic cells by natural killer cells. J Exp Med 2002; 195: 335-41.
[30] Andrews DM, Scalzo AA, Yokoyama WM, Smyth MJ, DegliEsposti MA. Functional interactions between dendritic cells and NK cells during viral infection. Nat Immunol 2003; 4: 175-81.

[31] Schmidt KN, Leung B, Kwong M, et al. APC-independent activation of NK cells by the Toll-like receptor 3 agonist double-stranded RNA. J Immunol 2004; 172: 138-43.

[32] Borg C, Jalil A, Laderach D, et al. NK cell activation by dendritic cells (DCs) requires the formation of a synapse leading to IL-12 polarization in DCs. Blood 2004; 104: 3267-75.

[33] Koka R, Burkett $\mathrm{P}$, Chien M, et al. Cutting edge: murine dendritic cells require IL-15R alpha to prime NK cells. J Immunol 2004; 173: 3594-8.

[34] Foti M, Granucci F, Ricciardi-Castagnoli P. A central role for tissue-resident dendritic cells in innate responses. Trends Immunol 2004; 25: 650-4.

[35] Vitale M, Della Chiesa M, Carlomagno S, et al. NK-dependent DC maturation is mediated by TNFalpha and IFNgamma released upon engagement of the NKp30 triggering receptor. Blood 2005; 106: 566-71.

[36] Tosi D, Valenti R, Cova A, et al. Role of cross-talk between IFNalpha-induced monocyte-derived dendritic cells and NK cells in priming $\mathrm{CD} 8+\mathrm{T}$ cell responses against human tumor antigens. J Immunol 2004; 172: 5363-70.

[37] Mocikat R, Braumuller H, Gumy A, et al. Natural killer cells activated by MHC class I(low) targets prime dendritic cells to induce protective CD8 T cell responses. Immunity 2003; 19: 561-9.

[38] Kelly JM, Darcy PK, Markby JL, et al. Induction of tumor-specific $\mathrm{T}$ cell memory by NK cell-mediated tumor rejection. Nat Immunol 2001; 3: 83-90.

[39] Adam C, King S, Allgeier T, et al. DC-NK cell cross talk as a novel CD4+ T-cell-independent pathway for antitumor CTL induction. Blood 2005; 106: 338-44.

[40] Ferlazzo G, Morandi B, D'Agostino A, et al. The interaction between NK cells and dendritic cells in bacterial infections results in rapid induction of NK cell activation and in the lysis of uninfected dendritic cells. Eur J Immunol 2003; 33: 306-13.

[41] Yu G, Xu X, Vu MD, Kilpatrick ED, Li XC. NK cells promote transplant tolerance by killing donor antigen-presenting cells. J Exp Med 2006; 203: 1851-8.

[42] Hayakawa Y, Screpanti V, Yagita H, et al. NK Cell TRAIL Eliminates Immature Dendritic Cells In Vivo and Limits Dendritic Cell Vaccination Efficacy. J Immunol 2004; 172: 123-9.

[43] Della Chiesa M, Vitale M, Carlomagno S, et al. The natural killer cell-mediated killing of autologous dendritic cells is confined to a cell subset expressing CD94/NKG2A, but lacking inhibitory killer Ig-like receptors. Eur J Immunol 2003; 33: 1657-66.

[44] van den Broeke LT, Daschbach E, Thomas EK, Andringa G, Berzofsky JA. Dendritic cell-induced activation of adaptive and innate antitumor immunity. J Immunol 2003; 171: 5842-52.

[45] Cooper MA, Fehniger TA, Fuchs A, Colonna M, Caligiuri MA. NK cell and DC interactions. Trends Immunol 2004; 25: 47-52.

[46] Buentke E, Heffler LC, Wilson JL, et al. Natural killer and dendritic cell contact in lesional atopic dermatitis skin--Malasseziainfluenced cell interaction. J Invest Dermatol 2002; 119: 850-7.

[47] Fehniger TA, Cooper MA, Nuovo GJ, et al. CD56bright natural killer cells are present in human lymph nodes and are activated by $\mathrm{T}$ cell-derived IL-2: a potential new link between adaptive and innate immunity. Blood 2003; 101: 3052-7.

[48] Martin-Fontecha A, Thomsen LL, Brett S, et al. Induced recruitment of NK cells to lymph nodes provides IFN-gamma for $\mathrm{T}(\mathrm{H}) 1$ priming. Nat Immunol 2004; 5: 1260-5.

[49] Kitamura $\mathrm{H}$, Iwakabe $\mathrm{K}$, Yahata $\mathrm{T}$, et al. The natural killer $\mathrm{T}$ (NKT) cell ligand alpha-galactosylceramide demonstrates its immunopotentiating effect by inducing interleukin (IL)-12 production by dendritic cells and IL-12 receptor expression on NKT cells. J Exp Med 1999; 189: 1121-8.

[50] Hermans IF, Silk JD, Gileadi U, et al. NKT cells enhance CD4+ and CD8+ T cell responses to soluble antigen in vivo through direct interaction with dendritic cells. J Immunol 2003; 171: 5140-7.

[51] Silk JD, Hermans IF, Gileadi U, et al. Utilizing the adjuvant properties of CD1d-dependent NK T cells in T cell-mediated immunotherapy. J Clin Invest 2004; 114: 1800-11.

[52] Montoya CJ, Jie HB, Al-Harthi L, et al. Activation of plasmacytoid dendritic cells with TLR9 agonists initiates invariant NKT cellmediated cross-talk with myeloid dendritic cells. J Immunol 2006; 177: 1028-39. 
[53] Pietra G, Romagnani C, Mazzarino P, et al. Comparative analysis of NK- or NK-CTL-mediated lysis of immature or mature autologous dendritic cells. Eur J Immunol 2003; 33: 3427-32.

[54] Campos-Martin Y, Colmenares M, Gozalbo-Lopez B, et al. Immature human dendritic cells infected with Leishmania infantum are resistant to NK-mediated cytolysis but are efficiently recognized by NKT cells. J Immunol 2006; 176: 6172-9.

[55] Yokota K, Ariizumi K, Kitajima T, et al. Cytokine-mediated communication between dendritic epidermal $\mathrm{T}$ cells and Langerhans cells. In vitro studies using cell lines. J Immunol 1996; 157: 1529-37.

[56] Wands JM, Roark CL, Aydintug MK, et al. Distribution and leukocyte contacts of gammadelta $\mathrm{T}$ cells in the lung. J Leukoc Biol 2005; 78: 1086-96.

[57] Skeen MJ, Freeman MM, Ziegler HK. Changes in peritoneal myeloid populations and their proinflammatory cytokine expression during infection with Listeria monocytogenes are altered in the absence of gamma/delta T cells. J Leukoc Biol 2004; 76: 104-15.

[58] Conti L, Casetti R, Cardone M, et al. Reciprocal activating interaction between dendritic cells and pamidronate-stimulated gammadelta T cells: role of CD86 and inflammatory cytokines. J Immunol 2005; 174: 252-60.

[59] Josien R, Heslan M, Soulillou JP, Cuturi MC. Rat spleen dendritic cells express natural killer cell receptor protein 1 (NKR-P1) and have cytotoxic activity to select targets via a $\mathrm{Ca} 2+-d e p e n d e n t$ mechanism. J Exp Med 1997; 186: 467-72.

[60] Vanderheyde N, Aksoy E, Amraoui Z, et al. Tumoricidal activity of monocyte-derived dendritic cells: evidence for a caspase-8dependent, Fas-associated death domain-independent mechanism. J Immunol 2001; 167: 3565-9.

[61] Vidalain PO, Azocar O, Lamouille B, et al. Measles virus induces functional TRAIL production by human dendritic cells. J Virol 2000; 74: 556-9.

[62] Hubert P, Giannini SL, Vanderplasschen A, et al. Dendritic cells induce the death of human papillomavirus-transformed keratinocytes. FASEB J 2001; 15: 2521-3.
[63] Vanderheyde N, Vandenabeele P, Goldman M, Willems F. Distinct mechanisms are involved in tumoristatic and tumoricidal activities of monocyte-derived dendritic cells. Immunol Lett 2004; 91: 99101.

[64] Trinite B, Chauvin C, Peche H, et al. Immature CD4- CD103+ rat dendritic cells induce rapid caspase-independent apoptosis-like cell death in various tumor and nontumor cells and phagocytose their victims. J Immunol 2005; 175: 2408-17.

[65] Taieb J, Chaput N, Menard C, et al. A novel dendritic cell subset involved in tumor immunosurveillance. Nat Med 2006; 12: 214-9.

[66] Chan CW, Crafton E, Fan HN, et al. Interferon-producing killer dendritic cells provide a link between innate and adaptive immunity. Nat Med 2006; 12: 207-13.

[67] Cavanaugh VJ, Deng Y, Birkenbach MP, Slater JS, Campbell AE. Vigorous innate and virus-specific cytotoxic T-lymphocyte responses to murine cytomegalovirus in the submaxillary salivary gland. J Virol 2003; 77: 1703-17.

[68] Homann D, Jahreis A, Wolfe T, et al. CD40L blockade prevents autoimmune diabetes by induction of bitypic NK/DC regulatory cells. Immunity 2002; 16: 403-15.

[69] Hanna J, Gonen-Gross T, Fitchett J, et al. Novel APC-like properties of human NK cells directly regulate $\mathrm{T}$ cell activation. J Clin Invest 2004; 114: 1612-23.

[70] Moser B, Brandes M. Gammadelta T cells: an alternative type of professional APC. Trends Immunol 2006; 27: 112-8.

[71] Brandes M, Willimann K, Moser B. Professional antigenpresentation function by human gammadelta T Cells. Science 2005 309: 264-8.

[72] Celestin J, Rotschke O, Falk K, et al. IL-3 induces B7.2 (CD86) expression and costimulatory activity in human eosinophils. J Immunol 2001; 167: 6097-104

[73] Brandes $\mathrm{M}$, Willimann $\mathrm{K}$, Lang $\mathrm{AB}$, et al. Flexible migration program regulates gamma delta T-cell involvement in humoral immunity. Blood 2003; 102: 3693-701. 